Revista Iberoamericana, Vol. LXXIV, Núm. 224, Julio-Septiembre 2008, 793-802

\title{
ESTRIDENCIAS Y SILENCIOS FEMENINOS: ENTRE PRINCESAS Y VÍRGENES
}

POR

Alicia Borinsky

Boston University

ESCENAS DE REPRESENTACIÓN

La mujer es un problema para las mujeres.

La mujer: el singular intimida por su generalización. Encadena a los lugares comunes del eterno femenino, fabrica las madres abnegadas, las novias encantadoras, las maestras ejemplares y nos devuelve caricaturas en la forma de una falsa comprensión de la experiencia femenina jugando a definir las vidas individuales en un continuo que las destaca como emanaciones de esa mujer abstracta y única, sombra de algún arquetipo que acecha con su intención disciplinaria. En ese sentido, la perplejidad en contraste con las certezas taxonómicas es arma crítica contra el falso conocimiento y la intención de adocenar y clasificar para una supuesta historia de la escritura femenina.

Por eso es necesario pensar a la vanguardia simultáneamente como momento histórico e instancia de lectura, dentro de un marco que permita entender lo individual. Este enfoque asume la discontinuidad y lo excéntrico como parte de la poética que surge con las vanguardias. Al mismo tiempo, privilegia las relecturas internas y a veces secretas con las cuales se preserva una conversación que recupera imágenes y redefine los contextos iniciales. La vanguardia no se restringe a sus inicios de principio de siglo en Latinoamérica. Un grupo nutrido de escritores y escritoras sigue siendo redescubierto por la crítica que va rehaciendo el grupo de lecturas obligatorias incluyendo, por ejemplo, a Felisberto Hernández, quien, como afirma Cortázar, es un escritor que hizo aquello que los surrealistas franceses prometieron pero no lograron hacer.

La escritura de la poesía vanguardista coincide con el comienzo de lo que se convertiría en la poesía del tango y del bolero, y que sería retomada más tarde por escritores como Manuel Puig y Guillermo Cabrera Infante, para nombrar sólo a quienes se interesaron más intensamente en esa poética. Las letras de bolero destacan el drama urbano de la mujer sola que en la calle es una perdida; de la soñadora que siempre va a una cita de amor; se ocupan del amor condenado al fracaso: "el beso que no me diste", "nosotros que nos queremos tanto/ debemos separarnos/no me preguntes más”; y de las tragedias que separan a los amantes.

El tango opera la transición entre el modernismo y la vanguardia con letras que hablan de muchachas que antes de su decadencia leían a Rubén Darío, y entre imágenes que nombran a las “autómatas del placer”, obreritas que empiezan a vestirse de satín y terminan devoradas por los placeres de la noche, construye un mundo siniestro y seductor. 
Como personajes, las mujeres solas como personajes son vistas en su excepcionalidad y peligro por la cultura popular y la poesía. Las escritoras son inventadas como personajes y recortadas de la historia literaria en una escena de representación de lo femenino que comparten personajes y escritoras.

Frecuentemente soslayadas por las historias literarias y artísticas más contemporáneas, las creadoras quedan fuera del juego colectivo y se prefiere hablar de excentricidades, dependientes, claro está, de la idea de la mujer como personaje universal y abstracto, aun cuando sea en oposición.

Así llegamos a las raras: la mujer niña Norah Lange, las suicidas como Alejandra Pizarnik, las de obra mínima y enigmática como Delmira Agustini, la empecinadamente apática María Luisa Bombal y las exitosas pero también fuera de serie: Clarice Lispector, Silvina Ocampo, Cristina Peri Rossi, Diamela Eltit. Casos únicos, sin interés ni impacto en la norma, y entretanto, las historias culturales nombran su centralidad en clave masculina, porque se supone que en la literatura escrita por mujeres raramente se encontrará algo distinto del discurso acerca de su propia naturaleza o la falta de pertenencia a la misma.

Esta mirada aísla, recorta y pone en vidriera a las mujeres, negándoles el papel definitorio de una instancia creativa y social que encontramos tan fácilmente otorgado a los escritores masculinos, continuamente estimulados para hablar de sus conexiones con la historia y la política del momento. A través de las mujeres se cultiva el rincón, el secreteo, la cosa que como algunos objetos evocados por Borges, es a la vez pequeña y demasiado pesada.

La crítica de género y el interés por la posmodernidad operan un fenómeno de contagio que redefine desde lo contemporáneo; el arte y la literatura empiezan a subsanar el hueco crítico con respecto a lo femenino.

Sugiero en estas páginas que una de las características de la peculiar escena de representación de lo femenino es la coexistencia transhistórica. Esto se debe a que no puede decirse que haya problemáticas dejadas de lado, sino que las discontinuidades más productivas señalan la posibilidad de encontrar una poética intersticial que, sin el aislamiento de una excentricidad extrema ni el adocenamiento gregario de las escuelas y generaciones literarias, permita entrever las cadenas de imágenes que inventan tanto personajes mujeres como autoras.

EL VIAJE DE LA PRINCESITA

La princesita de "Sonatina”(478-9) de Darío se interna en el siglo xx como una criatura enigmática cuya capacidad de suscitar el amor y la fascinación del hombre está en directa relación con una pasividad privilegiada, o con una perturbadora tendencia a la actividad maléfica cuando parece ejercer el derecho a una sensualidad propia. En "Sonatina" es una viajera frustrada que no logra convertirse en ninguno de los seres que le asegurarían una escapatoria propia:

¡Ay! La pobre princesa de la boca de rosa quiere ser golondrina, quiere ser mariposa, tener alas ligeras, bajo el cielo volar:

ir al sol por la escala luminosa de un rayo, 
saludar a los lirios con los versos de mayo,

o perderse en el viento sobre el trueno del mar.

El final feliz del poema trae a otro viajero que la rescatará de la muerte con el beso consagrado por la tradición para despertar a la Bella Durmiente. El encanto de la princesita reside en su palidez, en el ritmo de espera que la llevará a valorar aún más el amor prometido. Y, aunque ella misma no pueda marcharse, otro viene a buscarla para hacerle más llevadera la estadía:

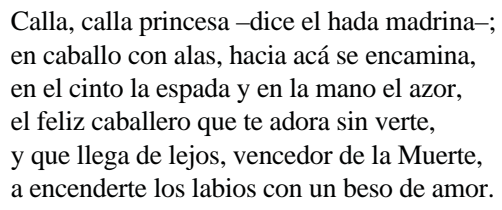

La princesita dejaría atrás su fracaso si tan sólo tuviera paciencia, porque el mundo de la acción y la anécdota no le pertenece; está hecha para esperar. "Sonatina” es un poema que ha formado parte del imaginario latinoamericano por varias generaciones. Con las evocaciones de la amada muerta en La amada inmóvil de Amado Nervo, donde la voluptuosidad que une pasión amorosa y muerte es enunciada como un secreto, nombra el encanto aparentemente irresistible de la mujer atada a un espacio unívoco impoluto, apartado de las contingencias históricas y cotidianas.

Es una imagen del amor que niega el placer físico y prestigia el desinterés por el cuerpo. El fantasma del culto a la virginidad circula en estos poemas y fue, sin duda, parte de lo que llevó a mantenerlos durante tantos años en las antologías destinadas al uso escolar.

Dice Nervo en el poema IX, titulado "Mi secreto":

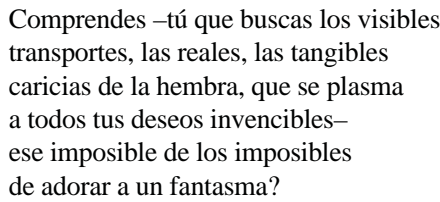

Ese tú que no comprendería el imposible de los imposibles, negado a la imaginación poética y al luto, no logra el estrellato del viudo inconsolable que recuerda, a su vez, sobre todo, la inmovilidad de su compañera como la forma más alta alcanzada por su fidelidad. El beso que devolvería la amada a la vida sería vulgar en este contexto.

Alejandra Pizarnik (Argentina, 1936-1972) forma parte de la vanguardia por su sensibilidad poética y visual. Estudió con el pintor surrealista Battle Planas y su primer libro recibió el encomio entusiasta de Octavio Paz. En un poema titulado "Sobre un poema de Rubén Darío” y co-dedicado a Marguerite Duras y a F. T. Montalvo, revisa la tradición armada por “Sonatina” e, implícitamente, por La amada inmóvil. La dedicatoria a Marguerite Duras sugiere la reinscripción de lo femenino en un registro intertextual. 
Pizarnik comparte con Duras la morosidad narrativa y la atención casi fotográfica a lo visual. Y, como Duras, no opta por el vitalismo sino por una forma radical de la apatía.

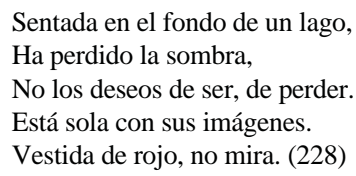

Está vestida de rojo pero no tiene suficiente interés en el mundo para mirar. El rojo no es aquí un color relacionado con la vitalidad. Es vínculo con la muerte, testimonio del interés de Pizarnik por la condesa sangrienta que en una serie de crímenes esteticistas narrados por Valentine Penrose ${ }^{1}$ en el libro titulado precisamente La condesa sangrienta asesinó a más de cien vírgenes para bañarse en su sangre con objetivos vagamente rejuvenecedores. La condesa circula en las alusiones al surrealismo de Cortázar ${ }^{2}$ y encarna para él una sexualidad prohibida y, por lo tanto, liberadora.

Para Pizarnik, la identidad de quien espera a quien vendrá por ella permanece virtual y su futuro acompañante es igualmente misterioso:

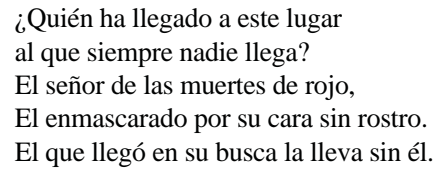

La pareja evocada por Pizarnik no lo es. Mientras que en "Sonatina", la princesa que espera y el caballero son interdependientes, en “Sobre un poema de Rubén Darío” se deshace la complementariedad. El hombre, señor de la sangre, no irá cuando se la lleve. Podrá desprenderse de sí mismo para anular el final feliz. Sin embargo, cumplirá su misión en una clave dada por el "la lleva sin él” con ecos de la pintura de Max Ernst y las ambigüedades de la identidad en un universo fantástico. ${ }^{3}$ Al final del poema ella puede mirar y cambia el

1 La condesa sangrienta fue Erzbeth Bathory (Hungría, 1560-1614). Su fama en Francia se debió a la publicación de un libro de Valentine Penrose (1898-1978) cuya pertenencia al grupo surrealista ubica su fascinación por los crímenes de la condesa en el mismo contexto del de los de Gilles de Rais y las prácticas del Marqués de Sade que tanto impacto tuvieron sobre ese sector de la vanguardia.

2 Sobre todo en 62, modelo para armar. Desde el comienzo, cuando el comensal hace alusión al castillo sangriento como un plato, la novela quiere que nos internemos en la existencia histórica de la condesa y su placer por el consumo de sangre.

3 Las relaciones entre Cortázar y Pizarnik son múltiples en este aspecto. En Axolotl, de Cortázar, el juego pronominal que nos permite dudar de si nos habla un ser humano o un axolotl, al final, es similar al tambaleo de la identidad que encontramos en Pizarnik. El fundador de esta problemática para la vanguardia entendida en su estricto sentido histórico en Argentina fue Macedonio Fernández, cuya teoría del almismo ayoico subyace a todos estos intentos. 
color de su ropa: "Vestida de negro, ella mira./La que no supo morirse de amor y por eso nada aprendió./Ella está triste porque no está”.

Paradójicamente, Pizarnik tiene algo en común con Amado Nervo. La pregunta con que se cierra el poema de Nervo: “[i $]$ ese imposible de los imposibles/de adorar a un fantasma?” no es imposible para Pizarnik. La voz que dice el poema de Pizarnik se adora a sí misma como fantasma, adora el fantasma en ella misma, la suspensión de la identidad, la huelga en contra de la anécdota. En una reescritura radical de Amado Nervo, Pizarnik es viuda de sí misma.

El poema de amor más intenso de la vanguardia está en el Canto II de Altazor de Vicente Huidobro. Allí se juega a la pérdida de la identidad en sentido opuesto al de Pizarnik. Si en Pizarnik hay una disminución de la esfera del yo, que con el fulgor de una depresión radicalizada deja vacía a la persona, dividida más allá de la expresión pronominal, en este poema de Huidobro la mujer cubre la esfera de lo visible y lo experimentable al punto de que verla por primera vez es reconocerla: "Te hallé como una lágrima en un libro olvidado/ Con tu nombre sensible desde antes en mi pecho” (403).

Sin la mujer es imposible conocer porque ella es también aquello que ve, da existencia al universo:

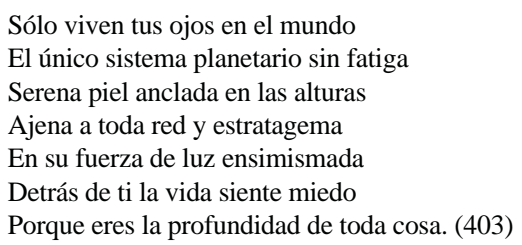

La mujer que ve es ya la mirada del hombre. Perfectamente integrada en una hipótesis amorosa que la expande universalmente, no puede desligarse de ese abrazo que la disgrega y disemina. Devorada por todo lo perceptible, la intensidad del amor desdice su existencia y le arrebata la posibilidad de ser contingente. Su papel en esta pareja es de una plenitud cuya representación confunde los límites entre el vacío de Pizarnik y la omnipresencia evocada por Huidobro.

La princesita enigmática llega al final de su viaje en Pizarnik pero tiene un instante intermedio en Altazor, cuando, rescatada de toda frivolidad, adquiere el prestigio de la vanguardia con un resultado idéntico al del modernismo: no conoceremos su palabra porque esta vez todo está imantado por su presencia, vuelta invisible manifestación del universo.

EL VIAJE DE LAS VÍRGENES

El imaginario social nos presenta a las vírgenes como portadoras de significados, vehículos para el deseo y el poder. En La batalla de las vírgenes, Rosario Ferré ${ }^{4}$ produce una novela a la vez paródica e informativa en torno a la sexualidad y la fe.

4 Rosario Ferré (Puerto Rico, 1938) escribe en inglés y en español. Fue una de las partícipes entusiastas del movimiento feminista puertorriqueño. 
En esta obra, Ferré busca nombrar ambos espacios: el de la mujer y las mujeres pensándose en una clave social que las aparta del espacio dedicado a las excepciones.

Interesa en la figura recortada por Rosario Ferré su ubicación. Practica una literatura que se nombra puertorriqueña y explora aquello que eso querría decir. En ese sentido y también ante la crítica, ofrece la posibilidad de preguntas acerca de cuestiones diferenciadas y únicas. No es una escritora latinoamericana que podamos interrogar en términos de la tradición compartida por viajes, amistades, historia y cenáculos que tanto anima la interpretación de las obras de sus contemporáneos nacidos en otros sitios americanos.

$\mathrm{Al}$ ser de Puerto Rico, tiene una relación única con Estados Unidos, aunque comparta hasta cierto punto el cosmopolitismo de los escritores latinoamericanos del siglo xx que se alimentan de Europa. Como puertorriqueña no está, sin embargo, entre aquellos que traen consigo la carga de explotación y victimización cultural que se respira en la obra de algunos de sus compatriotas.

Más que en el caso de los países de América Latina que han sido concebidos desde afuera en clave de revoluciones, dictaduras militares y más recientemente globalización, circula en torno a Puerto Rico el fantasma del pintoresquismo. Una isla hispánica de playas atractivas. Un espejismo de felicidad para el turismo o el “uptown” del “downtown” neoyorkino.

Hay un lugar común en las identidades culturales que nos defineal Caribe con características cuyo invariable determinismo meteorológico sólo puede suscitarnos escepticismo. Rosario Ferré, al escribir en inglés y en castellano, deja que cada una de las lenguas opere sus efectos de alusiones e interferencias, se deja operar por ellas y desarrolla un perfil propio, ya sea en la escritura directa en inglés o en la autotraducción. Más aguda que cualquier exploración explícita de los bordes que separan a una cultura de otra es su actitud: dejarse trabajar por la lengua; los lectores de su obra que se dedican al tema podrán llegar a conclusiones importantes sobre la política cultural puertorriqueña. ${ }^{5}$

La batalla de las vírgenes se inicia con un momento que conecta fe y situación económica. Mariana, la protagonista, regresa de Mallorca a Puerto Rico después de seis años de ausencia y nota que el chofer del taxi que la lleva a la ciudad del aeropuerto viene cargado con medallas de la Virgen. Sabremos que se trata de una virgen yugoslava que se ha instalado en la imaginación de los puertorriqueños con particular prestigio. En la novela, su imagen se exhibe en la vidriera de una agencia de viajes VIP firmemente asociada con el turismo caro. Así lo ve el taxista que dice a su pasajera: “A mí también me gustaría ir a Yugoslavia a ver la Virgen de Mejuugorje, pero no tengo dinero [...] Dicen que si uno lleva muchos rosarios, la Virgen se los convierte en oro, y con ellos el pasaje sale de cachete, añadió riendo estrepitosamente” (1-2).

La Virgen en singular implica que hay una sola Virgen, abstracta, universal. Pero el vínculo con el turismo y el marketing invitan a una mirada perpleja sobre las técnicas que hacen posibles la fe. La madre de Mariana es una de las seguidoras del culto de la Virgen y sostiene haber sido testigo de su aparición en una Polaroid. Mientras que los creyentes son frecuentemente presentados como resabios anacrónicos del pasado, aquí el sentimentalismo de la fe incluye una apreciación del modo de funcionamiento de una Polaroid:

5 Véase Middlebrooks (tesis 2004), bajo mi dirección, donde se estudian con atención el problema de la autotraducción y las políticas culturales del bilingüismo en la obra de Ferré. 


\begin{abstract}
Es algo maravilloso ver como la cara de la Virgen se va apareciendo poco en la foto, flotando sobre el agua del lago, o sobre una nube o árbol cualquiera [...] Y eso que no se ve nada, nadita, en el momento preciso. Los viernes (ella sólo se aparece los viernes), los peregrinos le rezan el rosario en la capilla, y a las cinco y media en punto el sol se pone a bailar, los pajaritos se callan y hay como una luz inefable que camina alrededor. En ese momento uno toma una foto del cielo con la Polaroid. ¡Y la Virgen sale claritita! Yo sé que la Virgen me va a ayudar, y que te va a ayudar a ti también. (2)
\end{abstract}

Como con los extraterrestres, las hipótesis sobre la posibilidad o imposibilidad de la veracidad de la aparición ponen en juego conjeturas acerca de la luz, radiaciones, fenómenos atmosféricos. Pero la novela se ocupa de los actores implícitos: las creencias populares y el ambiente en el cual se encarnan. Por eso las evocaciones de algún bolero, las marcas de objetos, las menciones de cómo se visten los personajes son más importantes que las características de su fe. Cada uno tiene, al principio de la obra, la fe que permite su presupuesto.

El culto de una virgen local, la Virgen del Pozo de Sábana Grande, tiene el prestigio negativo de lo marginal. Es venerada por los pobres de la isla pero el obispo manda excomulgar a quienes visitan su santuario. El culto a las vírgenes y a las santas es el tipo de ocasión que une a fieles en propósitos y esperanzas, y por eso es un excelente vehículo para tratar de entender a sus sociedades. De ahí el interés de la literatura de las Américas en el tema en los últimos tiempos.

El culto de la santa Muerte, recientemente novelado por Homero Aridjis en México, congrega a narcotraficantes, asesinos y gente común en una celebración de su poder para hacer entender algo acerca de la muerte, trasuntar un discurso que permita ubicarse en la violencia de México. La santa Muerte da miedo porque está ineludiblemente ligada al crimen y a lo marginal. Es una virgen para una era de gatillo fácil, muertes inexplicables, tratos que se malogran, sexo pensado patológicamente y barrios que se aíslan del resto porque se los ve como peligrosos.

Tomás Eloy Martínez inventa a partir del archivo histórico y político argentino que tan decisivamente contribuyó a formar en lo que atañe al peronismo, la figura de Santa Evita. Vemos allí a una Eva Perón que, biografiada a partir de las peripecias de su cadáver secuestrado y venerado en altares clandestinos, manifiesta la voluntad igualitaria de un pueblo en clave militante. Suya es la Argentina de una izquierda que llegó a la violencia inspirada por un mensaje equívoco y populista.

En la novela de Fernando Vallejo, La virgen de los sicarios, religión y fe juegan también un papel fundamental. Entrar a las iglesias de Medellín no logra borrar los asesinatos y actos sexuales prostituidos, la explotación de los niños, su capacidad para matar sin remordimientos. La vida de perros callejeros que llevan es dedicada a la virgen en gesto a la vez creyente y desafiante.

La visión de Aridjis parte de una fascinación con los cultos del México precolombino, en particular el de Coatlicue, y como tal permanece enfocado en la parte femenina de la atención a la santa. La novela de Fernando Vallejo se da en un registro misógino estridente cuya claridad no es diluida por la ironía que podría encontrársele.

Tomás Eloy Martínez convoca en su Santa Evita la voluptuosidad del deseo de interactuar con el cadáver, su poder. El diseño de la novela y el modo en que actúan los personajes 
puede verse en términos de la galería que, desde el modernismo hasta Juan Carlos Onetti, piensa a la mujer muerta como prisma diseminante de significados.

En La batalla de las vírgenes de Rosario Ferré también leemos la capacidad de suscitar significados de mujeres icónicas. Si la virgen importada de Yugoslavia trae consigo la capacidad de consumo de viajes y exotismo de una parte de la sociedad preparada para pensar que si los milagros existen, ocurren lejos, la local, la virgen del Pozo, es distinta.

La virgen del Pozo representa otra violencia que la conecta con las obras posteriores de los autores a quienes he aludido hace un momento. Se prohíbe su culto, se la segrega a zonas poco frecuentables y se desconfía de su capacidad. Sin embargo, los pobres la aman y la hacen suya, identificándola con Puerto Rico al punto de que la llegada de la virgen extranjera provoca una batalla que nos llega en la novela a través de un editorial, cosa que contribuye a darle un tono de objetividad y recortarla del discurso tentativo de la ficción.

Pasamos aquí de lo tentativo de la fe a la solidez de los hechos. Y leemos sobre una matanza acaecida cuando se celebran los cuarenta años de la primera aparición de la virgen del Pozo.

Se celebraba en ese lugar el aniversario de los cuarenta años de la primera aparición de la virgen del Pozo cuando cientos de peregrinos de los que acuden allí en guagua, en carro público o a pie, vieron llegar bocineando una impresionante caravana de Mercedes Benzes, BMWs, SAABs y otros carros de lujo que se adentraron atrevidamente por el parking. (118)

Se nos informa también que se trataba de una caravana de fieles de la Virgen yugoslava que había llegado esa mañana a Isla Verde.

Labatalla que sigue reproduce fielmente el temor que las clases altas sienten al ver a quienes consideran peligrosos por ser más pobres. La virgen yugoslava cae al suelo y es despojada de sus joyas y su manto, mueren personajes de la clase alta y todo termina, sin embargo, con un final feliz cuando se nos dice que una de las damas de sociedad, víctima del encuentro, había legado dinero para construir un santuario mucho más grande que el que quedó destruido para que se venerara, sin problemas de diferencias de clase, a santa María Invicta.

La desaparición de ambas vírgenes, englutidas por el conflicto de polarización clasista, se hace con el aire de una negociación política y de un cuento de hadas. Estas mujeres icónicas han logrado solucionar los problemas al ser dejadas de lado. Las clases altas, exotizadas al ser representadas por la virgen importada, financian las formas de la solución.

Este final sugiere que la expresión violenta de la diferencia de clase tiene remedio y que la manifestación conjunta de la fe en un santuario podría llegar a unir a Puerto Rico.

En esta lectura las aristas de la novela desaparecen completamente, pero hay otra que también se impone. Es la que pone en relieve las contradicciones del escurridizo personaje de Mariana, la mujer que protagoniza la novela y que guarda una relación dificultosa con las instituciones a las cuales pertenece. No ama a su marido, se divorcia de él; no es buena madre, tiene poca confianza en sus propias percepciones, pero su insatisfacción le hace seguir buscando alternativas vitales. Encerrada en un pabellón, cree haber encontrado en el otro final de la novela, después de los sucesos que opusieron a la Virgen yugoslava y la del Pozo, su verdadera fe: “Ariel tenía razón, Padre, peregrinar es siempre pasar a lo desconocido, salir hacia lo abierto. Sabíamos que en Puerto Rico ocurriría una matanza, habíamos oído rumores 
de que sucederían disturbios serios, pero no nos preocupamos por eso". Con una fe que se refugia a la vez en lo icónico y en lo inseguro, una mujer confía en los milagros de otra que, sin embargo, sólo puede ofrecerle algo oblicuo, una búsqueda. Escrita en español, la novela también alberga al inglés. La distinción clara entre el uso de ciertas palabras en un idioma o en otro es tan equivocada como el purismo con respecto a las vírgenes es la implicación de su textura.

Ni universales ni discernibles completamente en su individualidad, vírgenes como Mariana proponen un futuro para la fe en la forma de un paréntesis y un signo de interrogación. Acaso estas imágenes de mujeres, vírgenes de historieta y amantes desconcertadas, partícipes confundidas del culto pero fervientemente interesadas en representar a un país, brinden una clave para salir del rincón, rescatar al personaje de Mariana del pabellón en que termina encerrada, y cuestionar la interpretación patológica de su excentricidad.

ORÍGENES

En “Mujer saliendo del psicoanalista”, Remedios Varo ${ }^{6}$ pinta una figura de mujer erguida que camina con una cabeza de hombre en su mano. El aspecto general es el que estamos acostumbrados a asociar con su trabajo: la mujer es etérea, está vestida trans-históricamente con una toga casi transparente, tiene ojos almendrados y una mirada que podría ser de otro mundo. Su era es simultáneamente la de la alquimia y la ciencia ficción futurista y abre interrogantes sobre procedencia que sólo pueden ser resueltos parentéticamente. La salida del psicoanalista sugiere que se trata de la de su padre.

No hay sangre en el cuadro. Sólo la escena desleída de una broma indecible en torno a la paternidad que, con un guiño, propone que acompañemos a esta figura femenina en un viaje más allá de los orígenes, sin fundaciones, con árboles genealógicos y un museo de princesas, vírgenes y representaciones incesantemente destruidas y vueltas a armar.

\section{BiBLIOGRAFÍA}

Aridjis, Homero. La santa muerte. México: Alfaguara, 2004.

Cortázar, Julio. 62/modelo para armar. Buenos Aires: Sudamericana, 1968.

Darío, Rubén. Prosas profanas. Poesías completas. Buenos Aires: Antonio Zamora, 1967.

Eloy Martínez, Tomás. Santa Evita. Buenos Aires: Planeta, 1995.

Ferré, Rosario. La batalla de las vírgenes. San Juan: Editorial de la Universidad de Puerto Rico, 1993.

Huidobro, Vicente. Altazor. Obras completas I. Santiago: Andrés Bello, 1974.

Middlebrooks, Laura. "The Sexual Politics of Translation and the Work of Rosario Ferré and Esmeralda Santiago”. Tesis doctoral. Boston University, 2004.

${ }_{6}$ El cuadro de Remedios Varo (1908-1963) es de 1961. Con Leonor Fini, Leonora Carrington, Frida Kahlo, para nombrar sólo a algunas, Remedios Varo forma parte de una constelación de pintoras cuya obra se inicia en la vanguardia y sigue con sesgo propio después del momento de manifiestos y puntualizaciones políticas. 
Nervo, Amado. La amada inmóvil. Madrid: Cátedra, 2002.

Pizarnik, Alejandra. Obras completas. Poesía y prosa. Cristina Piña, ed. Buenos Aires: Corregidor, 1994.

Vallejo, Fernando. La virgen de los sicarios. Madrid: Alfaguara, 1994. 